\title{
Type A behaviour pattern: is it a risk factor for hypertension?
}

\author{
J.N. Al-Asadi
}

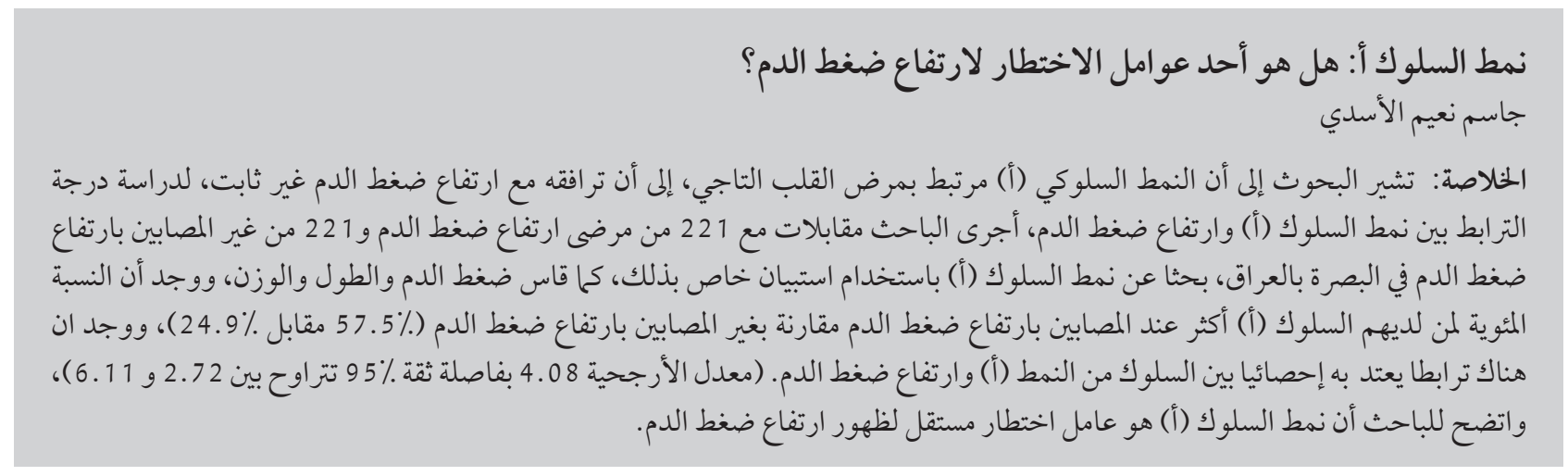

ABSTRACT Type A behaviour pattern has been found to be associated with coronary heart diseases, but its association with hypertension is inconsistent. To investigate the association between type A behaviour pattern and hypertension, 221 known hypertensive patients and a control group of 221 non-hypertensive patients in Basra, Iraq, were interviewed for type A behaviour using to a special questionnaire. Blood pressure, height and weight were measured. The proportion with type A behaviour was significantly higher in hypertensive than non-hypertensive patients (57.5\% versus $24.9 \%$ ) and a highly significant association was found between type A behaviour and hypertension (OR 4.08, 95\% Cl: 2.72-6.11). Type A behaviour pattern was shown to be an independent risk factor for the development of hypertension.

\section{Le schéma de comportement de type A est-il un facteur de risque d'hypertension?}

RÉSUMÉ II est apparu que le schéma de comportement de type A était associé aux coronaropathies, mais son association avec l'hypertension présente des contradictions. Afin d'étudier la relation entre le schéma de comportement de type A et l'hypertension, 221 patients hypertendus et un groupe témoin de 221 patients non hypertendus de Bassora (Iraq) ont été interrogés sur le comportement de type A au moyen d'un questionnaire spécial. Leur pression artérielle, leur taille et leur poids ont également été mesurés. Le pourcentage de patients présentant un comportement de type A était significativement plus élevé chez les hypertendus que chez les non hypertendus ( $57,5 \%$ contre $24,9 \%$ ) et une association très importante a été observée entre le comportement de type A et l'hypertension (odds ratio 4,08, intervalle de confiance à $95 \%: 2,72-6,11)$. Le schéma de comportement de type A est apparu comme un facteur de risque indépendant du développement de l'hypertension. 


\section{Introduction}

Individuals with "type A" personality tend to be competitive and ambitious and respond to stress with hostility or aggression [1], showing more pronounced haemodynamic responsiveness when there is a threat of failing [2]. The observation of stress-related sympathetic nervous system activity and increased catecholamine secretion in people with type A behaviour, resulting in a rise in blood pressure and heart rate, prompted the suggestion of an association with cardiovascular diseases [3].

Type A behaviour had been shown to be associated with an increased risk of coronary heart disease (CHD) [4]. It has been suggested that type A behaviour increases exposure to potential triggers to coronary events, rather than materially affecting the process of atherosclerosis [5]. Some researchers have suggested that individuals with type A behaviour may have greater cardiovascular reactivity under conditions of high job strain [6] or environmental conditions that are stressful or challenging [3]. Conversely, data indicating a similar association between type $\mathrm{A}$ behaviour and hypertension are inconsistent $[7,8]$. Such inconsistency may be due to the fact that hypertension status was based on a single measurement [9]. The results may also have been confused by the use of antihypertensive medication such as beta-adrenergic blocking drugs, which appear to reduce the vigorous vocal style and hostility of those with type A pattern [10,11].

Although many studies found an association between type A behaviour and cardiovascular diseases $[4,12]$, others did not $[13,14]$. Uncertainty in the definition of the global type A behaviour pattern itself may be an important part of this problem [13]. Others have suggested that only certain components of type A behaviour, such as hostility [15], time urgency and impatience [16] (referred to as "toxic" elements) are likely to be associated with the risk of CHD.
The aim of this case-control study in Iraq was to further investigate the hypothesis that type A behaviour is associated with hypertension.

\section{Methods}

A case-control study was undertaken in Basra, Iraq, from April to December 2007.

\section{Sample}

Patients were recruited from Al-Sadr teaching hospital and Al-Seef public medical clinic (a medical centre where patients with chronic diseases are registered and drugs for hypertension are distributed). The sample represented all eligible patients who attended either of the 2 medical centres during the study period and were available at one of the author's visits to these centres (3 times/ week for 2 hourseach visit). A total of 221 known hypertensive patients, currently on antihypertensive treatment, aged 26-74 years were chosen randomly. No patients refused to participate. A further 221 non-hypertensive patients aged 26-74 years who attended the same medical centres for illnesses other than hypertension were chosen as a control group. All the subjects were residents of Basra City centre.

Informed consent was obtained after explaining the aim of the study. Hypertensive patients were excluded if they reported having suffered myocardial infarction, congestive heart failure, stroke or angina pectoris. Pregnant women and those on contraceptive pills were also excluded. Control patients found to have systolic blood pressure $\geq 140 \mathrm{mmHg}$ and/or diastolic blood pressure $\geq 90 \mathrm{mmHg}$ at examination, i.e. identified as hypertensive for the first time, were excluded.

\section{Data collection}

Both groups were interviewed according to a special questionnaire which included sociodemographic data (age, sex, marital status, occupation, level of education), in addition to information about level of physical activity, smoking, history of diabetes mellitus and the presence of family history of hypertension. Family history was considered positive if one or more first-degree relative had hypertension.

The physical activity of subjects was defined as active (regular exercise $\geq 2$ hours/week), irregular (exercise $<2$ hours/week) or inactive (no type of exercise practised). Non-smokers were those who never smoked, current smokers those who smoked regularly, while ex-smokers were those who had stopped smoking more than 3 months before the study. Diabetes mellitus was based on self-reports of a diagnosis of diabetes and history of taking anti-diabetes medication. Weight and height were measured and the body mass index (BMI) was calculated using the Quetlet index [17]. Non-obese was defined as body mass index $<25 \mathrm{~kg} / \mathrm{m}^{2}$, overweight as BMI $25-29.9 \mathrm{~kg} / \mathrm{m}^{2}$ and obese as BMI $\geq 30 \mathrm{~kg} / \mathrm{m}^{2}$ [18].

\section{Definition and measurement of blood pressure}

Hypertension was defined according to the criteria of the Joint National Committee 7 th report, i.e. systolic blood pressure $\geq 140 \mathrm{mmHg}$ and/or diastolic blood pressure $\geq 90 \mathrm{mmHg}$ [19] or current use of antihypertensive medication, regardless of the recorded blood pressure measurement. A mercury sphygmomanometer with a suitable cuff size was used to measure blood pressure. After 5 minutes rest, the right arm blood pressure of a seated participant was assessed twice, 5 minutes apart, and the average was reported as the final blood pressure measurement.

\section{Assessment of type A behaviour}

To assess type A behaviour pattern, both the hypertensive and the control groups were interviewed according to a special questionnaire which was 
modified by Al-Lami from that of Friedman and Rosenman [20]. Re-phrasing and changes in wording were made to questions to make them easier to understand and resulted in an 18-item questionnaire based on a dichotomized (Yes/No) response format. The questionnaire was constructed to create 2 nominal variables: type A or non-type A behaviour [20]. The questionnaire contained 6 criteria for each of which there were 3 questions. Questions 1-3 were concerned with rapidity, 4-6 with impatience, 7-9 with competition and ambition, 10-12 with expressiveness, 13-15 with aggressiveness and 16-18 with need to control. Having 2 positive answers out of 3 questions for each criterion rendered that criterion positive, and having 5 criteria positive out of 6 denoted that the person has a type A behaviour pattern; otherwise the person was classified as having non-type A behaviour.

The changes to the original questionnaire were previously reviewed and approved by 5 specialists in the field of psychiatry, and the questionnaire was shown to be useful for assessing type A behaviour in Iraqi people $[21,22]$. The validity of the questionnaire was tested with the Framingham type A behaviour scale [23]; overall agreement rate was $82 \%$.

Before starting the study, the testretest reliability of the questionnaire was tested in a sample of 50 people with a 6-week retest interval; it yielded a coefficient of 0.79 . The reliability of the questionnaire was thus deemed adequate.

\section{Statistical analysis}

Statistical analysis was done using SPSS software package, version 15 . The results were expressed as numbers and percentages. The comparison of the frequencies of the studied parameters between cases and controls was done by the chi-squared test and the $t$-test was used for the differences between means. Logistic regression analysis was done to estimate the independent association of the studied risk factors with hypertension. Frequencies, odds ratios (OR) and confidence intervals (CI) are presented. A $P$-value $<0.05$ was considered statistically significant.

\section{Results}

As shown in Table 1, no significant differences were noted between cases and controls regarding any of the demographic characteristics studied: age, sex, education, marital status or occupation. The mean age [standard deviation

\begin{tabular}{|c|c|c|c|c|c|}
\hline \multirow[t]{2}{*}{ Variable } & \multicolumn{2}{|c|}{ Cases } & \multicolumn{2}{|c|}{ Controls } & \multirow[t]{2}{*}{$P$-value } \\
\hline & No. & $\%$ & No. & $\%$ & \\
\hline \multicolumn{6}{|l|}{ Age (years) } \\
\hline $26-35$ & 18 & 8.1 & 23 & 10.4 & \multirow[t]{5}{*}{0.82} \\
\hline $36-45$ & 62 & 28.1 & 62 & 28.1 & \\
\hline $46-55$ & 81 & 36.7 & 81 & 36.7 & \\
\hline $56-65$ & 49 & 22.2 & 44 & 19.9 & \\
\hline$>65$ & 11 & 5.0 & 11 & 5.0 & \\
\hline \multicolumn{6}{|l|}{ Sex } \\
\hline Male & 106 & 48.0 & 109 & 49.3 & \multirow[t]{2}{*}{0.74} \\
\hline Female & 115 & 52.0 & 112 & 50.7 & \\
\hline \multicolumn{6}{|l|}{ Education } \\
\hline Illiterate & 59 & 26.7 & 51 & 23.1 & \multirow[t]{5}{*}{0.89} \\
\hline Primary & 38 & 17.2 & 39 & 17.6 & \\
\hline Intermediate & 22 & 10.0 & 26 & 11.8 & \\
\hline Secondary & 37 & 16.7 & 37 & 16.7 & \\
\hline Basic university and more & 65 & 29.4 & 68 & 30.8 & \\
\hline \multicolumn{6}{|l|}{ Marital status } \\
\hline Married & 197 & 89.1 & 193 & 87.3 & \multirow[t]{3}{*}{0.65} \\
\hline Unmarried & 14 & 6.3 & 18 & 8.1 & \\
\hline Widowed/divorced & 10 & 4.5 & 10 & 4.5 & \\
\hline \multicolumn{6}{|l|}{ Occupation } \\
\hline Employed & 70 & 31.7 & 79 & 35.7 & \multirow[t]{3}{*}{0.40} \\
\hline Unemployed & 151 & 68.3 & 142 & 64.3 & \\
\hline Total & 221 & 100.0 & 221 & 100.0 & \\
\hline
\end{tabular}




\begin{tabular}{|c|c|c|c|c|c|}
\hline \multirow[t]{2}{*}{ Risk factor } & \multicolumn{2}{|c|}{ Cases } & \multicolumn{2}{|c|}{ Controls } & \multirow[t]{2}{*}{ OR $(95 \% \mathrm{CI})$} \\
\hline & No. & $\%$ & No. & $\%$ & \\
\hline Type A behaviour & 127 & 57.5 & 55 & 24.9 & \\
\hline Non-type A behaviour & 94 & 42.5 & 166 & 75.1 & \\
\hline \multirow[t]{2}{*}{ Total } & 221 & 100.0 & 221 & 100.0 & $4.08(2.72-6.11)$ \\
\hline & \multicolumn{4}{|c|}{$\chi^{2}=48.4, \mathrm{df}=1, P<0.001$} & \\
\hline
\end{tabular}

$O R=$ odds ratio; $C l=$ confidence interval; $d f=$ degrees of freedom .

(SD)] of the case group was 49.4 (SD 9.9) years while that of the controls was 48.3 (SD 10.2) years.

Table 2 shows that the prevalence of typeA behaviourwas significantly higher among the hypertensive patients compared with the control group: 127/221 (57.5\%) versus 55/221 (24.9\%) (OR 4.08, 95\% CI: 2.72-6.11, $P<0.001)$.

As shown in Table 3 , the percentage of smokers in the hypertension group (14.9\%) was comparable to the control group (13.6\%), but the percentage of ex-smokers among the hypertensives (11.3\%) was significantly higher than that in the non-hypertensives $(3.6 \%)$ $(P<0.01)$ and the proportion of nonsmokers in the hypertension group (73.8\%) was lower than that in the non-hypertension group (82.8\%). The percentages of overweight and obese patients were significantly higher in the hypertension group (43.4\% and 37.1\% respectively) than in the control group (36.2\% and $30.3 \%$ respectively) $(P<$ $0.01)$.
The other studied risk factors (i.e. physical inactivity, diabetes mellitus and family history of hypertension) were more prevalent in the hypertension group $(79.6 \%, 26.2 \%$ and $64.3 \%$ respectively) in comparison with the control group $(65.2 \%, 14.9 \%$ and $48.9 \%$ respectively) $(P<0.01)$.

To examine the independent effect of personality as a risk factor for hypertension, a logistic regression analysis was performed (Table 4). The studied variables were: age, sex, marital status,

\begin{tabular}{|c|c|c|c|c|c|c|}
\hline \multirow[t]{2}{*}{ Risk factor } & \multicolumn{2}{|c|}{ Cases } & \multicolumn{2}{|c|}{ Controls } & \multirow[t]{2}{*}{$P$-value } & \multirow[t]{2}{*}{ OR $(95 \% \mathrm{Cl})$} \\
\hline & No. & $\%$ & No. & $\%$ & & \\
\hline \multicolumn{7}{|l|}{ Smoking } \\
\hline Non-smokers & 163 & 73.8 & 183 & 82.8 & $<0.01$ & \\
\hline Ex-smokers & 25 & 11.3 & 8 & 3.6 & & \\
\hline Smokers & 33 & 14.9 & 30 & 13.6 & & $1.23^{\mathrm{a}}(1.06-1.59)$ \\
\hline \multicolumn{7}{|c|}{$\operatorname{Body}$ mass index $\left(\mathrm{kg} / \mathrm{m}^{2}\right)$} \\
\hline$<25$ & 43 & 19.5 & 74 & 33.5 & $<0.01$ & \\
\hline $25-29.9$ & 96 & 43.4 & 80 & 36.2 & & \\
\hline$\geq 30$ & 82 & 37.1 & 67 & 30.3 & & $2.10^{\mathrm{b}}(1.28-3.46)$ \\
\hline \multicolumn{7}{|c|}{ Physical activity level } \\
\hline Active & 21 & 9.5 & 36 & 16.3 & $<0.01$ & \\
\hline Irregular & 24 & 10.9 & 41 & 18.6 & & \\
\hline Inactive & 176 & 79.6 & 144 & 65.2 & & $2.10^{c}(1.28-3.74)$ \\
\hline \multicolumn{7}{|l|}{ Diabetes mellitus } \\
\hline Yes & 58 & 26.2 & 33 & 14.9 & $<0.01$ & \\
\hline No & 163 & 73.8 & 188 & 85.1 & & $2.03(1.26-3.27)$ \\
\hline \multicolumn{7}{|c|}{ Family history of hypertension } \\
\hline Yes & 142 & 64.3 & 108 & 48.9 & $<0.01$ & \\
\hline No & 79 & 35.7 & 113 & 51.1 & & $1.88(1.29-2.75)$ \\
\hline Total & 221 & 100.0 & 221 & 100.0 & & \\
\hline
\end{tabular}

${ }^{a}$ Smokers versus non-smokers.

${ }^{b}$ Body mass index $\geq 30 \mathrm{~kg} / \mathrm{m}^{2}$ versus $<25 \mathrm{~kg} / \mathrm{m}^{2}$.

cInactive versus active.

$O R=$ odds ratio; $C l=$ confidence interval. 


\begin{tabular}{lccc}
\hline \multicolumn{4}{l}{ Table 4 Logistic regression analysis of risk factors for hypertension } \\
\hline Risk factor & $\boldsymbol{\beta}$-coefficient & $\boldsymbol{P}$-value & OR (95\% Cl) \\
Personality type & 1.326 & $<0.001$ & $3.77(2.48-5.73)$ \\
Physical activity level & 0.431 & 0.005 & $1.54(1.14-2.08)$ \\
Family history of hypertension & 0.539 & 0.011 & $1.71(1.13-2.59)$ \\
Diabetes mellitus & 0.637 & 0.016 & $1.89(1.13-3.17)$ \\
Body mass index & 0.045 & 0.039 & $1.05(1.00-1.09)$ \\
\hline
\end{tabular}

$O R=$ odds ratio; $C l=$ confidence interval.

education, occupation, smoking, BMI, physical activity, family history of hypertension and diabetes mellitus, and personality type. Personality, physical activity, family history, diabetes mellitus and BMI were the only variables which showed a significant association with hypertension. Personality type was the risk factor most strongly associated with hypertension (OR 3.77, 95\% CI: 2.48-5.73).

\section{Discussion}

It should be emphasized that in evaluating self-administered questionnaires, type A individuals are often unaware of many of their behavioural patterns, or will deny them. Furthermore, no single type A individual should be expected to exhibit all the characteristics of type A behaviour [24]. To overcome such limitations, personal interviews were used in this study, since it has been found that personal interviews are more accurate than self-reported questionnaires [25]

The results of our study show that the type A behaviour pattern was significantly more prevalent in patients with hypertension (57.5\%) than in non-hypertensive people (24.9\%) (OR 4.08). This is in agreement with the findings of Irvine et al. [26] and Yan et al. [27], although the prevalence of type A behaviour among hypertensive patients in the present study (57.5\%) was lower than that reported by Irvine et al. (78\%) [26]. This difference may be because the people studied by Irvine et al. were untreated hypertensive patients whereas in the present study they were patients on antihypertensive medication. It has been found that antihypertensive drugs particularly beta-adrenergic blocking drugs may affect some characteristics or modify the expression of type A behaviour $[10,11,13]$. The difference may also be attributed to sociocultural differences or to psychosocial variability, since it has been found that there are intra-individual, inter-individual and inter-population psychosocial variability [27]. It is also believed that type A behaviour is influenced by cultural values in some modern societies that reward those who can produce with great amounts of speed, efficiency and aggressiveness [28].
Physical inactivity, obesity, family history of hypertension and diabetes mellitus are well-known predictors of hypertension [29-31], and all these factors were significantly more prevalent in the hypertension than the control group. However, these factors did not eliminate the increased risk of hypertension that was associated with type A behaviour (as shown by the logistic regression analysis). Smoking is also a risk factor for hypertension but the percentage of ex-smokers among the hypertension group (11.3\%) was greater than that among the control group (3.6\%). This might be because patients with hypertension recognized the harmful effects of smoking or had been advised by a physician to quit smoking.

In conclusion, the present study provides some evidence of an association between type A behaviour and hypertension in the Iraqi population. Type A behaviour can be viewed not as a fixed personality trait but as the outcome of a set of predispositions that interact with specific situations that elicit certain behaviour [32]. Singer et al. have pointed out that employees can learn to utilize more relaxed working styles if demands and deadlines at work and fear of job loss are diminished to a more acceptable level [33]. Therefore, interventions such as counselling and behaviour therapy to identify objectionable and maladaptive behaviours and replace them with healthier types of behaviour, and health education to avoid stressful situations, may reduce the need for more harmful antihypertensive medication.

\section{References}

1. Martin RA, Kupier NA, Westra HA. Cognitive and affective components of the type A behavior pattern: preliminary evidence for a self-worth contingency model. Personality and Individual Differences, 1989, 10:771-778.

2. Lucini $\mathrm{D}$ et al. Hemodynamic and autonomic adjustments to real life stress conditions in humans. Hypertension, 2002, 39:184-188.

3. Matthews KA, Jennings R. Cardiovascular responses of boys exhibiting the type A behavior pattern. Psychosomatic Medicine, 1984, 46(6):484-497.
4. Yoshimasu K, and the Fukuoka Heart Study Group. Relation of type A behavior pattern and job-related psychosocial factors to non-fatal myocardial infarction: a case-control study of Japanese male workers and women. Psychosomatic Medicine, 2001, 63:397-404.

5. Gallacher JEJ et al. Is type A behavior really a trigger for coronary heart disease events? Psychosomatic Medicine, 2003, 65(3):339-346.

6. Burns TW, Hutt J, Weidner G. Effects of demand and decision latitude on cardiovascular reactivity among coronary-prone women and men. Behavioral Medicine, 1993, 19:122-128. 
7. Thieorell R et al. Psychosocial and physiological factors in relation to blood pressure at rest-a study of Swedish men in their upper twenties. Journal of Hypertension, 1985, 3:591-600.

8. Shin EH et al. Blood pressure and symptoms of depression and hostility: A prospective study. American Journal of Hypertension, 2001, 14(7):660-664.

9. Labre MM et al. Blood pressure stability of normotensives and mild hypertensives in different settings. Health Psychology, 1988, 7:127S-137S.

10. Schmieder R et al. The influence of beta blockers on cardiovascular reactivity and type A behavior pattern in hypertensives. Psychosomatic Medicine, 1983, 45:417-423.

11. Krantz DS et al. Comparative effects of two beta-blockers on cardiovascular reactivity and type A behavior in hypertensives. Psychosomatic Medicine, 1988, 50:615-626.

12. Mattioli AV et al. The relationship between personality, socioeconomic factors, acute life stress and the development, spontaneous conversion and recurrences of acute lone atrial fibrillation. Europace, 2005, 7:211-220.

13. Shekelle RB et al. The MRFIT Behavior Pattern Study II: type A behavior and incidence of coronary heart diseases. American Journal of Epidemiology, 1985, 122:559-570.

14. Pickering $\mathrm{T}$ et al. Behavioral cardiology-has its time finally arrived? Mount Sinai Journal of Medicine, 2003, 70(2):101-112.

15. Hart KE. A moratorium on research using the Jenkins activity survey for type A behavior. Journal of Clinical Psychology, 1997, 53:905-907.

16. Cole SR et al. Time urgency and risk of non-fatal myocardial infarction. International Journal of Epidemiology, 2001, 30:363-369.

17. Frier BM et al. Nutritional factors in health and disease. In: Haslett et al., eds. Davidson's principles and practice of medicine, 18th ed. London, Churchill Livingstone, 2001.

18. Obesity: preventing and managing the global epidemic. Geneva, World Health Organization, 2000 (WHO Technical Report Series, No. 894)

19. Chobanian AV et al. Seventh report of the Joint National Committee on Prevention, Detection, Evaluation and Treatment of Hypertension. Journal of the American Medical Association, 2003, 289(19):2560-2572.

20. Al-Lami FH. Riskfactors analysis of myocardial infarction among younger Iraqi patients, a case control and follow up study [PhD thesis]. Baghdad, Iraq, Department of Community Medicine, University of Baghdad, 1997.

21. Al-Bayati SM. Type A personality in Iraqi patients with duodenal ulcer. Saudi Medical Journal, 2003, 24(3):313-314.

22. Al-Asadi JN, Habib OS, Al-Naama LM. Cardiovascular risk factors among college students. Bahrain Medical Bulletin, 2006, 28(3):126-130.

23. Haynes SG et al. The relationship of psychosocial factors to coronary heart disease in the Framingham study, 1. Methods and risk factors. American Journal of Epidemiology, 1978, 107:362-383.

24. Rosch PJ. Stress and cardiovascular disease. Comprehensive Therapy, 1983, 9(10):6-13.

25. Herman $\mathrm{S}$ et al. Type As who think they are type Bs: discrepancies between self-ratings and interview ratings of the type $A$ (coronary-prone) behaviour pattern. British Journal of Medical Psychology, 1986, 59:83-88.

26. Irvine $J$ et al. Prevalence of type A behavior in untreated hypertensive individuals. Hypertension, 1991, 18:72-78.

27. Yan LL et al. Psychosocial factors and risk of hypertension: the Coronary Artery Risk Development in Young Adults (CARDIA) Study. Journal of the American Medical Association, 2003, 290:2138-2148.

28. Lachar BL. Coronary prone behavior. Texas Heart Institute Journal, 1993, 20:143-151.

29. Niskanen L et al. Inflammation, abdominal obesity, and smoking as predictors of hypertension. Hypertension, 2004, 44:859865.

30. Sharma AK, Bhardwaj S, Chaturvedi S. Predictors of hypertension in an urban Indian population. Indian Heart Journal, 2006, 58:21-27.

31. Chan GC. Type 2 diabetes mellitus with hypertension at primary healthcare level in Malaysia: are they managed according to guidelines? Singapore Medical Journal, 2005, 46(3):127-131.

32. Matthews KA, Haynes SG. Type A behavior pattern and coronary disease risk update and critical evaluation. American Journal of Epidemiology, 1986, 123:923-960.

33. Singer JA, Neale MS, Schwartz GE. Conflicting perspectives on stress reduction in occupational setting: a system approach to their solutions. In: Cataldo MF, ed. Health and industry: a behavioral medicine perspective. New York, John Wiley, 1986:162-192. 